\title{
Análise do comportamento dos consumidores de produtos ecologicamente corretos no município de São Gabriel: $O$ caso dos produtos orizícolas certificados com selo ambiental do IRGA
}

\author{
Analyzing the behavior of consumers of ecologically correct products: the case of rice products certified with IRGA's \\ environmental label
}

\section{Graciela Rodrigues Trindade', Ana Júlia Teixeira Senna², Alexandra Augusti Boligon ${ }^{3}$, Ricardo Ribeiro Alves ${ }^{4}$}

I, 2, 3, 4 UNIPAMPA, Campus São Gabriel, RS, Brasil

\section{Resumo}

Os hábitos de vida, consumo e a produção industrial, tem se sustentado, ao longo dos anos, a partir do uso indiscriminado dos recursos ambientais, prejudicando os ecossistemas e comprometendo a qualidade ambiental. Visando minimizar estes impactos, surgiu a produção mais limpa, que busca no processo produtivo, conservar matérias primas e energia, eliminar resíduos tóxicos e emissões de poluentes e, nos produtos, o enfoque é a redução dos impactos negativos ao longo do seu ciclo de vida. A cadeia produtiva orizícola foi uma das pioneiras na certificação de arroz com o selo ambiental, na produção de energia a partir da casca de arroz, e na adoção de tecnologias mais limpas. Porém, não se sabia o nível de informação dos consumidores em relação a essas práticas e ao desenvolvimento de produtos certificados com o selo ambiental. Por isso, este trabalho tem como objetivo caracterizar o comportamento dos consumidores de produtos ecologicamente corretos no município de São Gabriel (RS). Entrevistaram-se, cento e cinquenta e cinco consumidores, em cinco supermercados do município de São Gabriel (RS). Este município possui aproximadamente 29.000 ha de arroz cultivados (IBGE, 2009) e uma propriedade rural certificada com o selo ambiental do IRGA na safra 2009/2010. Os achados desta pesquisa servem para auxiliar na definição da embalagem do arroz certificado com o selo ambiental do IRGA, nas escolhas dos pontos de venda que distribuirão o produto, nas estratégias de comunicação a serem adotadas e na definição dos mercados que absorverão o produto final certificado.

Palavras-chave:Arroz. Embalagem Ecologicamente Correta. Marketing Ambiental. Selo Ambiental. Sustentabilidade.

\begin{abstract}
Lifestyles, consumption and industrial production have, over the years, been supported by the indiscriminate use of environmental resources, harming the ecosystems and jeopardizing environmental quality. The need to minimize these impacts gave rise to clean production systems, consisting in production processes geared towards preserving raw materials and energy, eliminating toxic wastes and polluting emissions and, with regard to products, the idea is to reduce their negative impacts along their life cycle. The rice production chain was one of the pioneers in the certification of eco-friendly rice products, in the production of energy from rice husk, and in the use of cleaner technologies. However, what was not known was the level of information of the consumers regarding these practices and the development of products certified with the environmental seal. Therefore, the goal of this paper is to characterize the behavior of the consumers who have opted for ecologically correct products in the municipality of de São Gabriel (RS). One hundred and fifty-five consumers were interviewed, in five supermarkets in the town of São Gabriel (RS). The area planted to rice in this municipality reaches approximately 29,000 hectares (IBGE, 2009) and one rural holding certified with IRGA's environmental Seal in the 2009/10 crop year. The findings of this survey will be a good help for defining the type of packaging for the rice certified with IRGA's environmental seal, for selecting the retail outlets responsible for distributing the product, for the communication strategies to be used and for defining the markets that are to absorb the certified final product. Keywords:Rice. Ecologically Correct Packaging. Environmental Marketing. Environmental Seal. Sustainability.
\end{abstract}




\section{INTRODUÇÃO}

Inúmeras pesquisas realizadas no século XX, segundo Dias (2009), revelaram que os recursos naturais não são ilimitados. Ao longo dos anos o consumo e a produção industrial vêm prejudicando os ecossistemas e comprometendo a qualidade ambiental, pois os hábitos de vida, tem se sustentado, a partir do uso indiscriminado dos recursos ambientais (Berté, 2009). Hoje, há uma preocupação crescente da sociedade e das empresas quanto ao futuro dos recursos naturais e o suprimento de recursos fósseis (energia) e minerais (matéria-prima) (Dias, 2009).

A degradação do meio ambiente é uma consequência das atividades econômicas praticadas no planeta. O crescimento populacional mundial ao longo da história exige áreas cada vez maiores para a produção de alimentos e, também, técnicas de cultivo que aumentem a produtividade da terra. Produtos químicos não biodegradáveis, usados para aumentar a produtividade e evitar predadores nas lavouras, matam microrganismos decompositores, insetos e aves, reduzem a fertilidade da terra, poluem os rios e águas subterrâneas e contaminam os alimentos. A urbanização multiplica esses fatores de desequilíbrio (Dias, 2009; Gliessman, 2009; Vinícius, 2010).

O conceito de desenvolvimento sustentável busca a preservação dos recursos naturais atuais para o usufruto também das gerações futuras. O desenvolvimento sustentável está baseado no equilíbrio dinâmico de três elementos: o ambiental, o social e o econômico (Dias, 2009; Gliessman, 2009; Philippi Jr. et al., 2004).

Uma das soluções à problemática ambiental é a modificação de comportamentos, atitudes e estilo de vidas, que poderão se refletir num consumo sustentável. Para que se produzam resultados, as ações de produção mais limpas requerem mudanças direcionadas à minimização de impactos ambientais através de práticas ambientais e sociais adequadas e responsáveis, como a criação de políticas nacionais focadas nesta temática e avaliação de alternativas tecnológicas. Restabelecer o respeito na convivência dos seres humanos com os outros seres vivos implicará numa nova ética em relação à natureza (Dias, 2009; Milaré, 2007).

A produção mais limpa busca no processo produtivo, conservar matérias primas e energia, eliminar resíduos tóxicos e as emissões de poluentes. Já nos produtos, o enfoque é a redução dos impactos negativos ao longo do seu ciclo de vida, desde a extração de matérias primas até sua disposição final. Por fim, nos serviços, busca-se a incorporação da questão ambiental no planejamento e na entrega ao consumidor final (Milaré, 2007).

\section{FUNDAMENTAÇÃO TEÓRICA}

A seguir, serão descritos o referencial teórico sobre a sustentabilidade do setor orizícola, a caracterização do composto de marketing ambiental do arroz e o comportamento dos consumidores.

\section{I SUSTENTABILIDADE DO SETOR ORIZÍCOLA}

Um dos sistemas que introduziu práticas agrícolas mais sustentáveis foi o sistema de produção orizícola. O principal instituto de pesquisa do arroz no Estado do Rio Grande do Sul que adotou essa prática de tecnologias mais limpas foi o Instituto Rio Grandense do Arroz -IRGA.

O Instituto Rio Grandense do Arroz tem manifestado a sua preocupação com os impactos ambientais causados pela atividade orizícola. O Instituto busca promover o desenvolvimento sustentável do setor orizícola, através da geração e difusão de conhecimentos, informações e tecnologias e, em decorrência disso, elaborou um projeto denominado "Projeto 10 - Lavoura Arroz RS", que serve para orientar as melhores práticas de manejo da lavoura de forma a minimizar os impactos e aumentar a produtividade.

Posterior a implantação do Projeto 10, esta instituição criou, em parceria com outros órgãos, o Selo ambiental da Lavoura de Arroz Irrigado do Rio Grande do Sul.

O selo ambiental da lavoura de arroz irrigado do RS foi criado em 2008, para a safra 2008/2009, e tem como finalidade (Bechert, 2010; Rosa, 2009):

- Promover a sustentabilidade ambiental e o processo de certificação e rastreabilidade;

- Garantir ao produtor reconhecimento quanto ao uso de práticas ambientais na lavoura de 
arroz irrigado;

- Tornar possível a agregação de valor ao produto e a ampliação de mercado;

- Reduzir custos agregados ao processo produtivo e ampliar os limites de crédito.

Diante da ausência de identificação da embalagem do produto beneficiado e da necessidade de valorizar o preço do produto final pago ao produtor, este trabalho tem como objetivo caracterizar o comportamento dos consumidores de produtos ecologicamente corretos, no município de São Gabriel, RS, com o intuito de subsidiar o setor orizícola com informações que apoiem a tomada da decisão de implantação de uma embalagem ambientalmente correta para o arroz com o selo ambiental.

Faz-se necessário o entendimento da utilização de marketing ambiental tanto na área rural quanto urbana, pois o aumento do consumo acarretou no aumento da produção e, consequentemente, no crescimento dos resíduos gerados, como embalagens, oriundos dos produtos consumidos (Dias, 2009).

\subsection{COMPOSTO DE MARKETING AMBIENTAL DO ARROZ}

O marketing consiste no processo de planejamento e implementação do desenvolvimento, da formulação de preço, promoção e distribuição de idéias, mercadorias e serviços para criar trocas que satisfaçam os objetivos individuais e organizacionais, tendo como metas avaliar as necessidades dos consumidores e satisfazê-los (Kotler, 2000). Portanto, para que o marketing ocorra, é preciso ter duas ou mais partes com necessidades não satisfeitas; o desejo e a capacidade de satisfazê-las; comunicação entre as partes e algo para trocar (Berkowitz et al, 2003).

A história do arroz começa com referências vindas da China de cinco mil anos atrás, embora haja indícios que possa ser originário da Índia. O gênero Oryza engloba cerca de vinte e três espécies, dispersas espontaneamente nas regiões tropicais da Ásia, África e das Américas (Embrapa, 2010).

Destaca-se como uma das principais culturas em dezessete países da Ásia e do Pacífico, de oito países Africanos, sete da América Latina, Caribe e do Oriente Médio. Como reconhecimento da importância do arroz e da sua trajetória histórica e humana, a ONU proclamou em 2004 como o Ano Internacional do Arroz - AIA (FAO, 2010).

O cultivo desse cereal no Brasil assume importância social, econômica e política desde os tempos coloniais alimentando escravos e colonizadores (IRGA, 2010).

Considera-se o arroz um alimento completo devido à sua importância na dieta humana, sua composição química e suas características nutricionais como fonte de energia por conter macro e micronutrientes em quantidades adequadas, pois o cereal contém alto teor de amido, fornecendo proteínas, lipídios, vitaminas e minerais. São nutrientes essenciais e devem estar presentes na alimentação diariamente por estarem diretamente relacionados à saúde da população. O seu déficit pode provocar doenças ou disfunções e o excesso intoxicações (Deon, 2010; FAO, 2010).

A distribuição comercial tem como princípio distribuir os produtos do produtor ao consumidor final na quantidade exigida, no momento desejado e no lugar onde se pretende comprar (Dias, 2009; Kotler, 2000; Tuleski, 2009).

Nos dias atuais, além de sua função primordial de proteger o produto, a embalagem atua também como uma poderosa ferramenta de marketing, com várias tarefas de venda, desde atrair a atenção do consumidor até descrever o produto, informar ao consumidor e realizar a venda (Kotler e Armstrong, 1999).

A embalagem é um item importante no composto de marketing, além de exercer a função de transportar, estocar produtos, identificá-los, também exerce o poder de sedução, cativando o consumidor, despertando desejos e levando-o ao ato da compra, que é a ação comprovadora da eficiência do marketing aplicado.

Quanto à promoção do produto ecologicamente correto a empresa precisa identificar as possíveis diferenças de produto, serviços, recursos humanos e imagem que podem ser estabelecidos em relação à concorrência. Selecionar e sinalizar estratégias de comunicação de produtos ecologicamente corretos para destacar sua diferença em relação à de seus concorrentes junto ao mercado alvo e desenvolver sua imagem, para que este mercado compreenda e aprecie o que ela oferece em relação a seus concorrentes. Como por exemplo, mostrar ao consumidor os benefícios do produto ecologicamente correto (Dias, 2009).

Expor o diferencial do produto ecologicamente correto, em relação ao convencional, para o 
consumidor e a criação da imagem deste produto são essenciais, pois transmitem os valores de respeito e qualidade ao meio ambiente.

Vinícius (2010), diz que a forma de desenvolvimento econômico atual estimula o desperdício, pois os produtos são planejados para durarem pouco. O apelo ao consumo multiplica a extração de recursos naturais: embalagens sofisticadas e produtos descartáveis não recicláveis nem biodegradáveis aumentam a quantidade de lixo no meio ambiente. A necessidade de aumentar as exportações para sustentar o desenvolvimento interno estimula tanto a extração dos recursos minerais como a expansão da agricultura sobre novas áreas, crescendo assim o desmatamento e a exploração excessiva da terra.

A geração de resíduos é inevitável em todo processo produtivo, conforme Dias (2009). Com isso, busca-se uma maneira de se agregar valor ao produto no final de seu ciclo de vida útil. Deve-se pensar ecologicamente em obter um ciclo de vida do produto que seja o mais circular possível, sendo incorporado de novo ao processo produtivo como matéria prima. É preciso incluir junto as preocupações tradicionais (fabricação do produto, satisfação das necessidades do consumidor com menor custo) novas preocupações como a minimização dos impactos ambientais totais gerados, características dos produtos, prevenção de contaminação, reutilização e/ou reciclagem ao final do ciclo de vida, dentre outros. Isso tudo evidencia o aumento da complexidade enfrentada pelas organizações e sistemas produtivos sustentáveis.

\subsection{COMPORTAMENTO DOS CONSUMIDORES}

O marketing estuda o campo do comportamento do consumidor, objetivando obter oportunidade de receber informações estratégicas para o desenvolvimento de novos produtos, suas características, preços, canais de distribuição, mensagens e outros elementos do composto de marketing, visando atender e satisfazer às necessidades e aos desejos dos consumidores na hora da compra (Kotler, 2000; Vieira, 2002).

São vários os fatores internos e externos que influenciam o processo de tomada de decisão de compra dos consumidores. Para entendermos o estudo do comportamento do consumidor, é importante analisar o modelo de estímulo e resposta demonstrado na Figura 1.

A tarefa do profissional de marketing é compreender as atividades, obter, dispor de produtos e serviços, entender o que estimula o comprador incluindo o marketing, o ambiente, os processos decisórios que antecedem e sucedem estas ações até a decisão de compra.

\begin{tabular}{|l|l|}
\hline $\begin{array}{c}\text { Estímulos de } \\
\text { marketing }\end{array}$ & \multicolumn{1}{|c|}{$\begin{array}{c}\text { Outros } \\
\text { estímulos }\end{array}$} \\
\hline Produto & Econômico \\
Preço & Tecnológico \\
Praça & Político \\
Promoção & Cultural \\
\hline
\end{tabular}

\begin{tabular}{|l|l|}
\hline $\begin{array}{c}\text { Características do } \\
\text { comprador }\end{array}$ & \multicolumn{1}{|c|}{$\begin{array}{c}\text { Processo de decisão do } \\
\text { comprador }\end{array}$} \\
\hline Culturais & $\begin{array}{l}\text { Reconhecimento de problemas } \\
\text { Busca de informações } \\
\text { Sociais }\end{array}$ \\
Pessoais & $\begin{array}{l}\text { Avaliação de alternativas } \\
\text { Decisão de compra } \\
\text { Psicológicos }\end{array}$ \\
& Comportamento após a compra \\
\hline
\end{tabular}

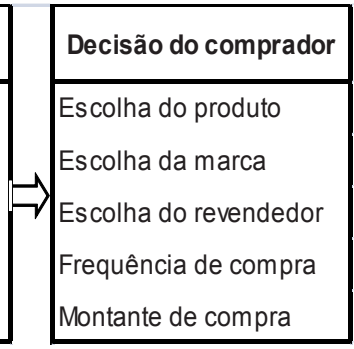

Figura 1 - Modelo de estímulo e resposta.

Fonte: Kotler (2000).

Na percepção de Kotler (2000), o comportamento dos consumidores é determinado principalmente por fatores culturais, além, dos fatores sociais, pessoais e psicológicos. Os profissionais de marketing estão interessados nos papéis e na influência destes fatores sobre o consumidor, ou seja, procuram identificar os grupos de ocupação com interesses comuns em seus produtos e serviços, visando satisfazer as necessidades e os desejos dos clientes alvo.

\subsection{FATORES CULTURAIS}

Exercem ampla influência sobre os consumidores. Segundo Kotler (2000), o comportamento do consumidor está relacionado aos valores culturais, religião, regiões geográficas, percepções, preferências, comportamentos familiares e outras instituições. Estes fatores são determinantes para suas necessidades e escolhas. As classes sociais, também, estão inseridas neste contexto, pois, não somente são determinadas pela renda, mas também, pelo modo de comportamento semelhante entre pessoas 
de mesma classe social, como na escolha de vestuários, padrões de linguagem, grau de instrução, preferências de atividades e lazer, por produtos e marcas de diversos segmentos.

\subsubsection{FATORES SOCIAIS}

Estão relacionados a grupos de referências, família, amigos, colegas de trabalho, religião, expondo a pessoa a um novo comportamento e estilo de vida, influenciando nas suas atitudes e autoestima (Kotler, 2000). Sua posição o define em cada grupo, determinando qual o seu papel, status na sociedade e comportamento de compra.

\subsubsection{FATORES PESSOAIS}

Para Medeiros e Cruz (2006), os fatores pessoais são determinados pelas características particulares das pessoas, os quais acabam por interferir nos seus hábitos e nas suas decisões de consumo. De acordo com Kotler (2000), estes fatores são moldados conforme a idade e o estágio do ciclo de vida da pessoa, ocupação, situação financeira, estilo de vida e personalidade.

\subsubsection{FATORES PSICOLÓGICOS}

A escolha na hora da compra é influenciada por quatro fatores, conforme Kotler (2000):

- Motivação: quando a necessidade passa a ser um motivo a um determinado nível de necessidade levando a pessoa a agir;

- Percepção: quando a pessoa seleciona, organiza e interpreta as informações recebidas internas ou externas;

- Aprendizagem: mudança do comportamento através da experiência por meio de impulsos, estímulos, sinais, respostas e reforços;

- Crenças e atitudes: são pensamentos, avaliações, sentimentos e tendências a respeito de alguma coisa.

A decisão de compra do consumidor varia conforme a marca, fornecedor, quantidade, ocasião ou ainda, formas de pagamento. As compras rotineiras envolvem menos decisões.

Uma gestão estratégica atual que está cada vez mais inserida nas organizações é a responsabilidade socioambiental. Esta forma de reconhecimento à sustentabilidade em seus negócios assegura melhores resultados tanto para a organização quanto para a sociedade (Aligleri et al., 2009).

Ainda conforme Aligleri et al. (2009), o consumidor assume a consciência socioambiental, através da disseminação das informações descritas nos encartes, espaços e disposição desses produtos nas gôndolas. Esta imagem institucional diferenciada e vinculada à causa ambiental contribui com:

- Educação ambiental junto à comunidade;

- Hábitos e melhor qualidade de vida;

- Formação de cidadãos capacitados, críticos e conscientes;

- Embalagens com menor impacto ambiental;

- Reconhecer produtos de menor impacto ambiental;

- Orientação e informação no ato da compra;

- Redução do lixo gerado na cidade;

- Geração de emprego e renda para as comunidades carentes;

- Produto menos agressivo ao meio ambiente.

A seguir, será descrita a metodologia utilizada nesta pesquisa.

\section{METODOLOGIA}

Primeiramente, realizou-se uma pesquisa bibliográfica em documentos, revistas, artigos científicos e trabalhos publicados pelo IRGA sobre a sustentabilidade do setor orizícola, a caracterização do composto de marketing ambiental do arroz e o comportamento dos consumidores. 
Posteriomente, foi construído um roteiro de entrevistas (Apendice A), articulado com o referencial teórico, direcionado aos consumidores de supermercados, totalizando vinte e uma questões, divididas em cinco grupos, conforme descritos a seguir:

- Primeiro grupo: três questões sobre a caracterização do consumidor.

- Segundo grupo: cinco questões referentes ao produto ecologicamente correto, hábito de reciclar, geração e desperdícios de resíduos e materiais, escolha de produto ecologicamente correto, conhecimento das práticas ecológicas e selo ambiental na lavoura de arroz.

- Terceiro grupo: três questões sobre o preço ecologicamente correto. Buscaram-se informações sobre o produto ecologicamente correto, se pagariam mais "caro" por esse produto e quanto a "mais".

- Quarto grupo: quatro questões sobre a distribuição do arroz ecologicamente correto. Buscou-se entender se o consumidor reconhece um produto ecologicamente correto nas prateleiras do supermercado, seus benefícios à saúde e a credibilidade desse produto.

- Quinto grupo: seis questões sobre a promoção do produto ecologicamente correto. Buscou-se verificar se há a divulgação das práticas ambientais, da embalagem ecológica, do selo ambiental e do produto final arroz ecologicamente correto.

Na sequência, foram realizadas as entrevistas com aplicacao do questionário aos consumidores nos supermercados do município de São Gabriel (RS). As entrevistas foram aplicadas pessoalmente, a cento e cinquenta e cinco consumidores com o intuito de identificar os hábitos dos consumidores em relação ao consumo de produtos ecologicamente corretos em cinco supermercados localizados no município de São Gabriel - RS.

\section{RESULTADOS E DISCUSSÃO}

A seguir, serão descritos os resultados das entrevistas com os consumidores dos supermercados de São Gabriel - RS.

\section{I Perfil dos entrevistados}

Em relação à frequência com que os consumidores entrevistados costumam efetuar suas compras nos supermercados no município de São Gabriel, a Figura 2, ilustra que 21\% dos entrevistados costumam ir semanalmente ao supermercado, $19 \%$ diariamente, $14 \%$ duas vezes por semana, $13 \%$ de três a quatro vezes por semana, $12 \%$ raramente vão supermercado, $11 \%$ têm o hábito de ir mensalmente e $10 \%$ frequentam o supermercado quinzenalmente.



Figura 2 - Frequência de compra no supermercado dos consumidores. 
Percebe-se que a maioria dos consumidores efetua suas compras semanalmente, seguida pela frequência diária, em função de compras de produtos hortifrutigranjeiros e de padaria que são produtos perecíveis.

A Figura 3 mostra a renda mensal dos entrevistados. Cerca de $46 \%$ recebem de dois a quatro salários mínimos nacionais, $29 \%$ até um salário mínimo, 20\% responderam estar sem renda fixa no momento, $4 \%$ recebem de cinco a sete salários mínimos e apenas $1 \%$ recebe acima de dez salários mínimos.

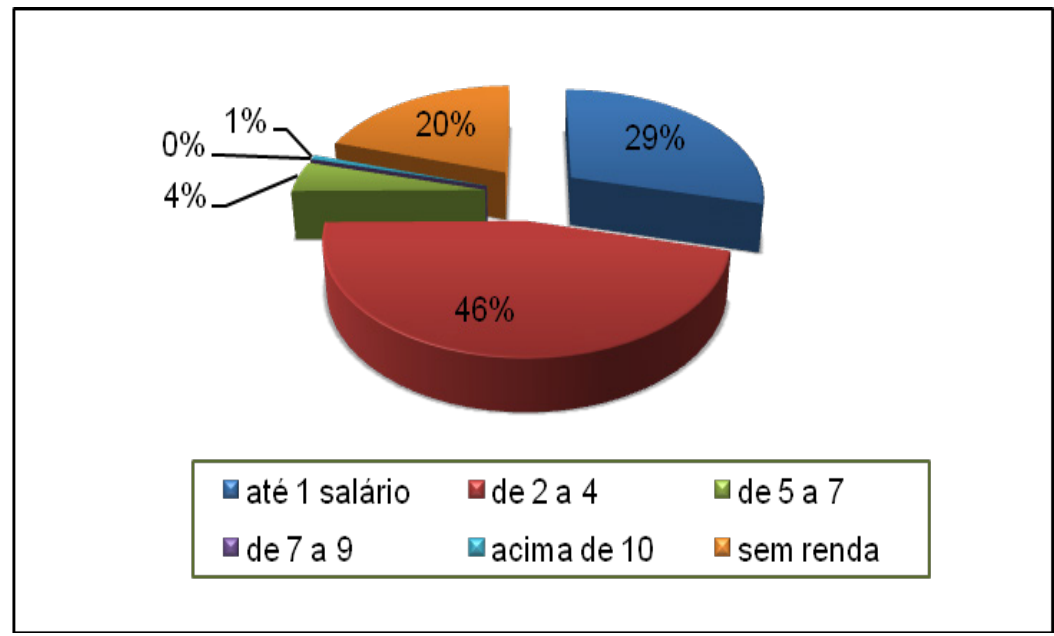

Figura 3 - Renda mensal em salários mínimos nacionais.

Observou-se mediante os levantamentos de dados mencionados acima, que a renda dos consumidores entrevistados varia de um a quatro salários mínimos.

Com relação ao nível de escolaridade dos consumidores entrevistados, a Figura 4, ilustra que $30 \%$ tinham o ensino fundamental incompleto, $29 \%$ ensino médio completo, $15 \%$ haviam começado o ensino superior, $9 \%$ disseram ter completado o ensino superior, $8 \%$ ensino médio incompleto, $5 \%$ ensino fundamental completo e $4 \%$ disseram não ter estudo.

Percebe-se mediante as respostas dos entrevistados que a maioria não completou a primeira etapa de ensino, seguida por consumidores que haviam completado as séries intermediárias. Portanto, é notável o baixo nível de instrução dos consumidores entrevistados.

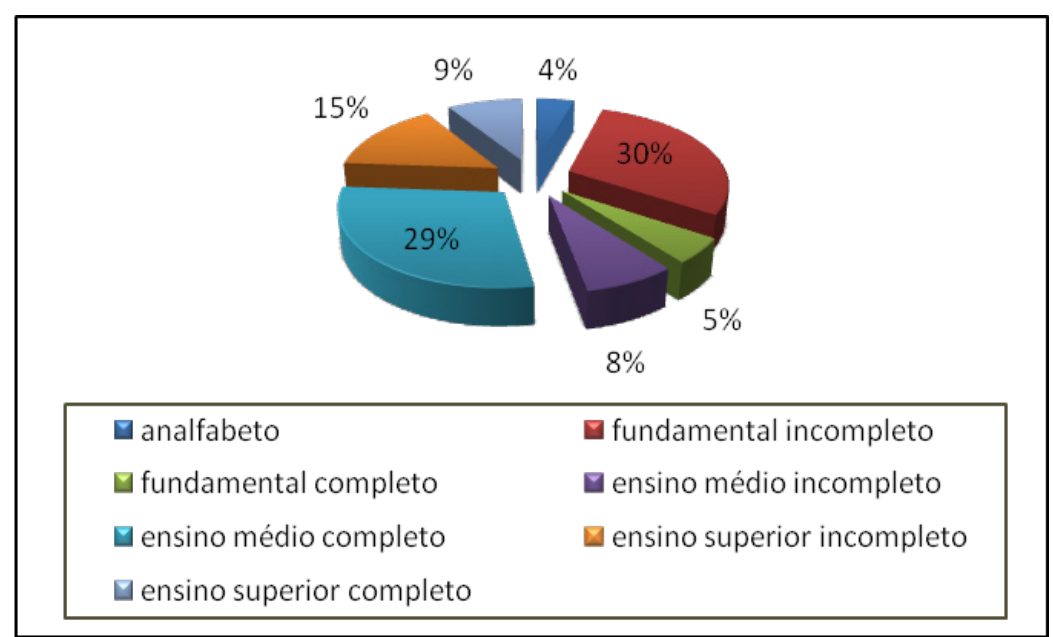

Figura 4 - Escolaridade dos entrevistados. 
Dias (2009) destaca que o aumento do nível de escolaridade contribui para a adoção de um comportamento ecologicamente correto, porém, este por si só, não resolverá os problemas ambientais e sim a mudança de comportamento, atitudes e estilos de vida, ou seja, a reflexão de um consumo sustentável. Isso ajuda a explicar o fato de que os respondentes não estão muito preocupados com os impactos negativos ao ambiente natural. Seria necessário um programa de educação ambiental que informasse este público e promovesse estas mudanças comportamentais.

\subsection{Produto eCOlogicamente CoRreto}

A Figura 5 ilustra os resultados obtidos quanto ao consumo consciente dos consumidores entrevistados. Cerca de 38\%, fazem reciclagem, 26\% afirmaram não adotar nenhuma das práticas mencionadas, $17 \%$ reutilizam materiais, $19 \%$ dos entrevistados consomem apenas o necessário, evitando a geração de lixo tanto em casa como no local de trabalho.

Percebe-se que os consumidores estão preocupados em fazer algum tipo de separação de resíduos (por exemplo, o lixo orgânico do lixo seco) aumentando a vida útil dos produtos e evitando desperdícios dos recursos.

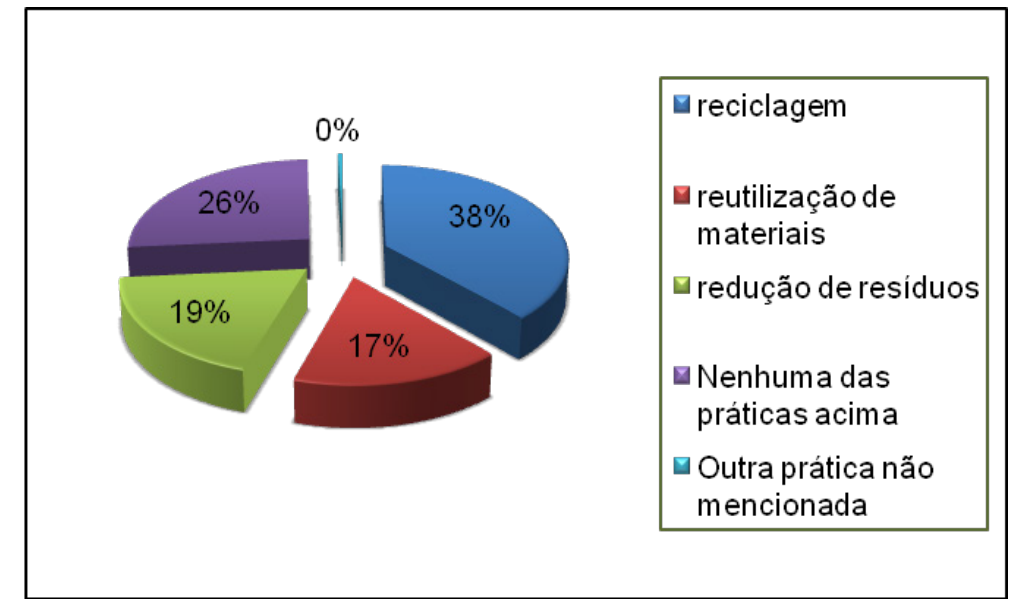

Figura 5 - Consumo consciente dos entrevistados.

Quanto a escolha do produto ecologicamente correto nos supermercados, conforme ilustra a Figura 6, 54\% dos entrevistados nunca se preocuparam em escolher produtos ecologicamente corretos, $26 \%$ raramente compram este tipo de produto e $20 \%$ tem uma compra consciente em relação ao produto escolhido nas gôndolas do supermercado.

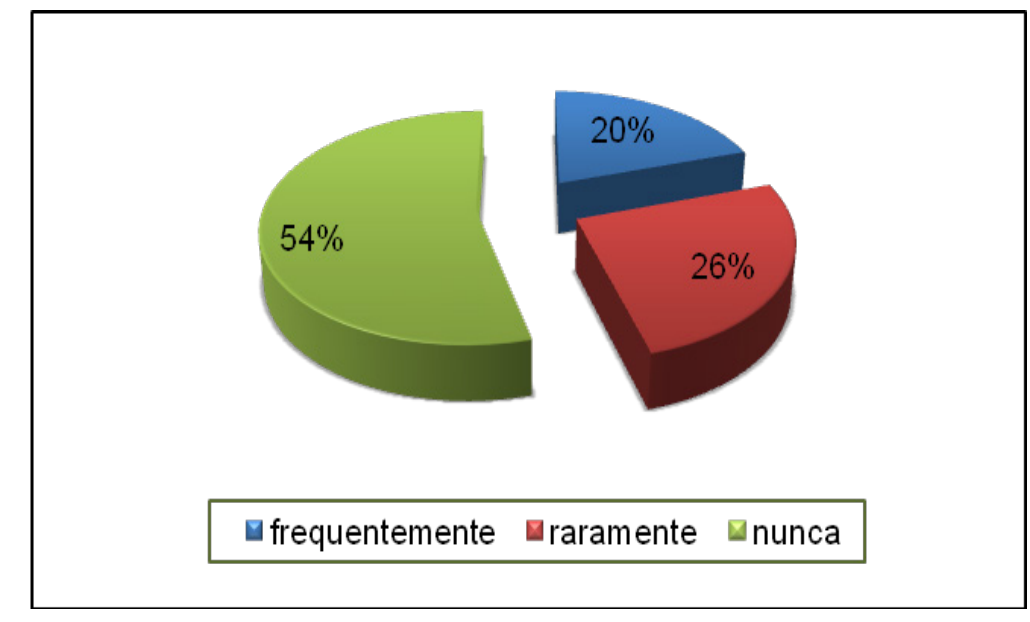

Figura 6 - Escolha de produto ecologicamente correto no supermercado. 
É perceptível que o consumidor não se preocupa com a escolha de produtos ecologicamente corretos, mesmo sabendo que esses produtos visam minimizar os impactos causados ao ambiente e à saúde, conforme demonstra os resultados acima. No ato da compra, o produto ecologicamente correto não é um atrativo de diferencial para o consumidor final, e sim o preço da mercadoria. É importante, portanto, diferenciar e destacar os benefícios dos produtos ambientalmente corretos nas gôndolas do supermercado.

Com relação à qualidade do produto ecologicamente correto comparado ao produto convencional, $60 \%$ dos entrevistados afirmaram que há diferença na qualidade desses produtos, $34 \%$ nunca compararam o produto convencional com o produto ecologicamente correto e apenas $6 \%$ disseram não ter diferença entre esses produtos (Figura 7).

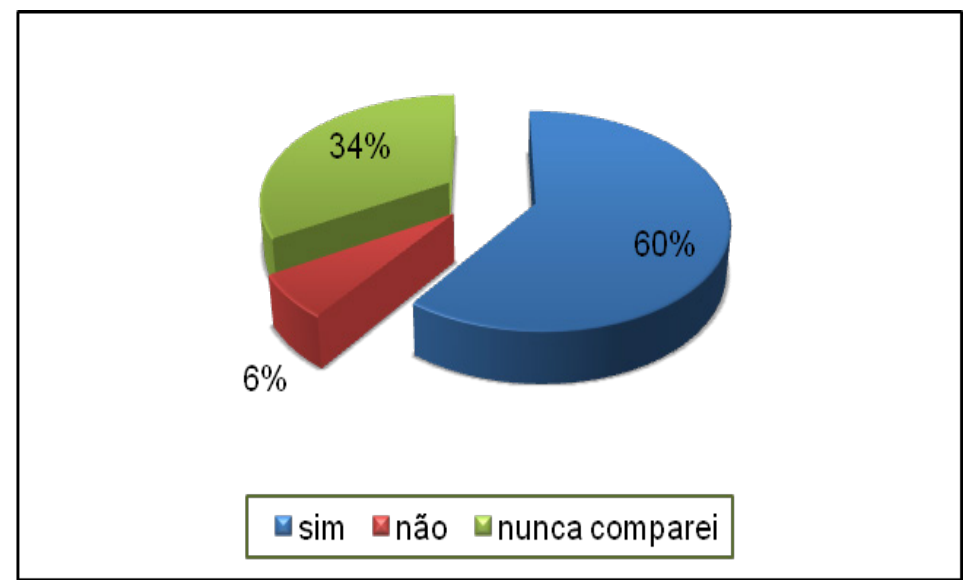

Figura 7 - Qualidade do produto ecologicamente correto e do convencional.

A Figura 7 mostra que o consumidor está ciente de que esse produto ecologicamente correto é benéfico à saúde, mais saboroso e sua qualidade é superior ao convencional, no que tange principalmente a sua produção.

Conforme ilustra a Figura 8, os consumidores quando questionados sobre o conhecimento das práticas ecológicas adotadas na lavoura de arroz no Estado do Rio Grande do Sul, dos cento e cinquenta e cinco entrevistados, cento e onze não tem conhecimento, vinte e oito consumidores pouco conhecem e dezesseis afirmaram ter conhecimento dessas práticas na lavoura.

No que se refere ao selo ambiental da lavoura de arroz irrigado do RS, a maior parte dos respondentes não têm conhecimento dessa certificação (cento e vinte e seis consumidores), quatorze consumidores pouco conhecem e quinze afirmaram ter conhecimento do selo ambiental (Figura 8).

Conforme os respondentes, há pouca divulgação das práticas ecologicamente corretas de manejo na lavoura orizícola e do Selo Ambiental, que é o prêmio de reconhecimento ao produtor e a propriedade rural por adotar tais práticas.

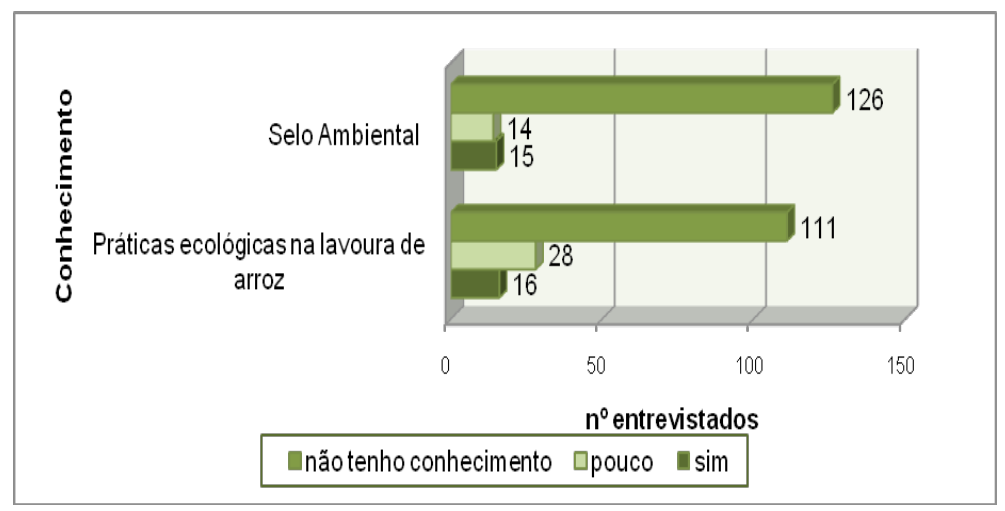

Figura 8 - Conhecimento do selo ambiental e das práticas ecológicas adotadas na lavoura de arroz irrigado no RS. 


\subsection{Preço ecologicamente Correto}

Quanto à demanda por produtos ecologicamente corretos, cento e trinta entrevistados afirmam estar aumentando o interesse por estes produtos e vinte e cinco respondentes disseram que não. Das pessoas entrevistadas, cento e quarenta e cinco declararam que o produto ecologicamente correto poderá despertar uma consciência eco social, educando, por exemplo, os consumidores e a indústria. Apenas dez asseguraram que não desperta essa consciência (Figura 9).

Verificou-se que a procura de produtos ecologicamente corretos está aumentando e conscientizando tanto a indústria, devido ao grande número de diversos produtos ecologicamente corretos para comercialização, como também o consumidor, este em pequena escala, mas está crescendo.

O aumento da produção de produtos ecologicamente corretos no Brasil tem levado os agricultores a buscar pontos mais diversificados para a comercialização. Em relação a essa questão, a Figura 9 mostra os resultados obtidos nas entrevistas, onde verifica-se que cem entrevistados pagariam "mais" por um produto ecologicamente correto e com certificação e cinquenta e cinco acham que não deveriam

Observa-se que o consumidor está disposto a pagar um diferencial por um produto ecologicamente correto.

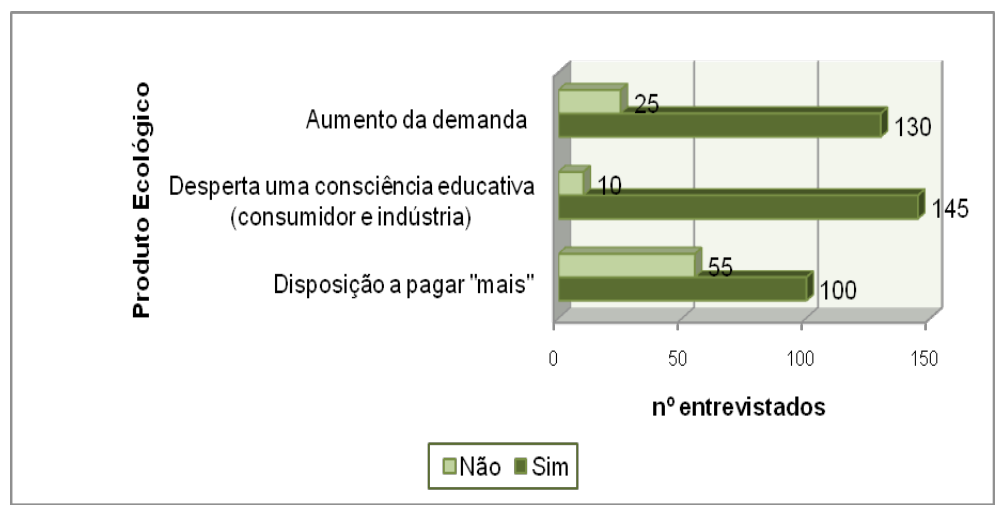

Figura 9 - O Produto ecologicamente correto pode despertar uma demanda ecológica.

Cerca de $85 \%$ dos consumidores questionados estão dispostos a pagar até $10 \%$ a "mais" por esse produto ecologicamente correto e certificado, $11 \%$ pagariam de 11 a $30 \%$ a mais; somente $2 \%$ dos respondentes pagariam entre 31 a $50 \%$ e; $2 \%$ pagariam o dobro do preço dependendo do produto oferecido (Figura 10).

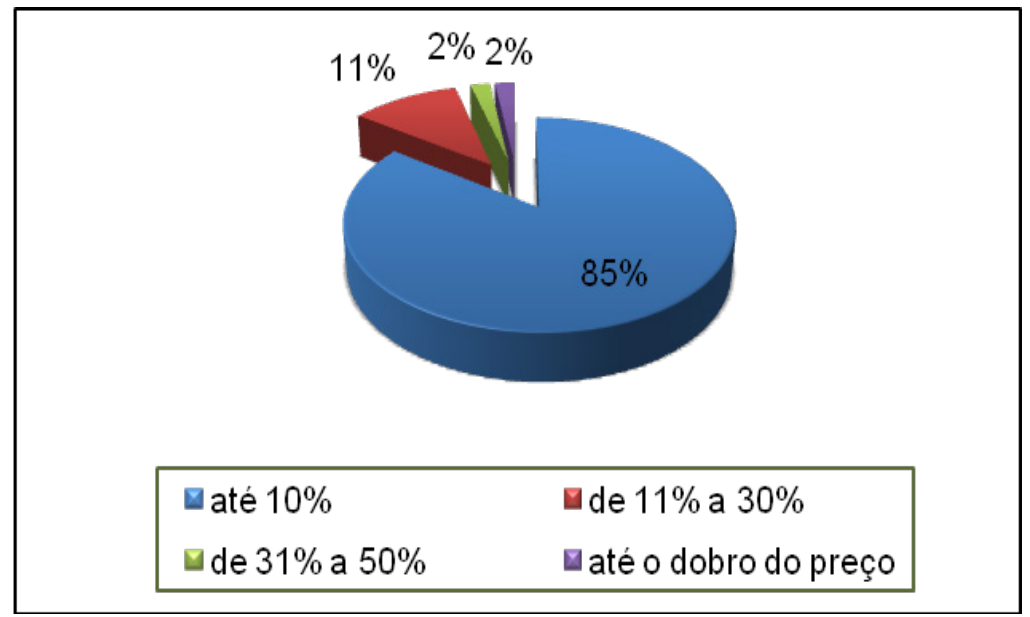

Figura 10 - Quanto a "mais" estariam dispostos a pagar por esse produto ecologicamente correto e certificado. 


\subsection{DISTRIBUIÇÃO DO PRODUTO ECOLOGICAMENTE CORRETO}

Referente ao reconhecimento de um produto ecologicamente correto nas prateleiras do supermercado, $35 \%$ dos consumidores assumem que reconhecem um produto ecologicamente correto, $21 \%$ afirmam não reconhecer, $28 \%$ pouco reconhecem e $16 \%$ confirmaram nunca ter percebido esses produtos nas prateleiras (Figura 11).

Observou-se que a maioria dos consumidores reconhecem um produto ecologicamene correto nas prateleiras do supermercado, porém alguns assumem não reconhecer o produto, devido a essas mercadorias estarem misturadas nas prateleiras junto aos produtos convencionais.

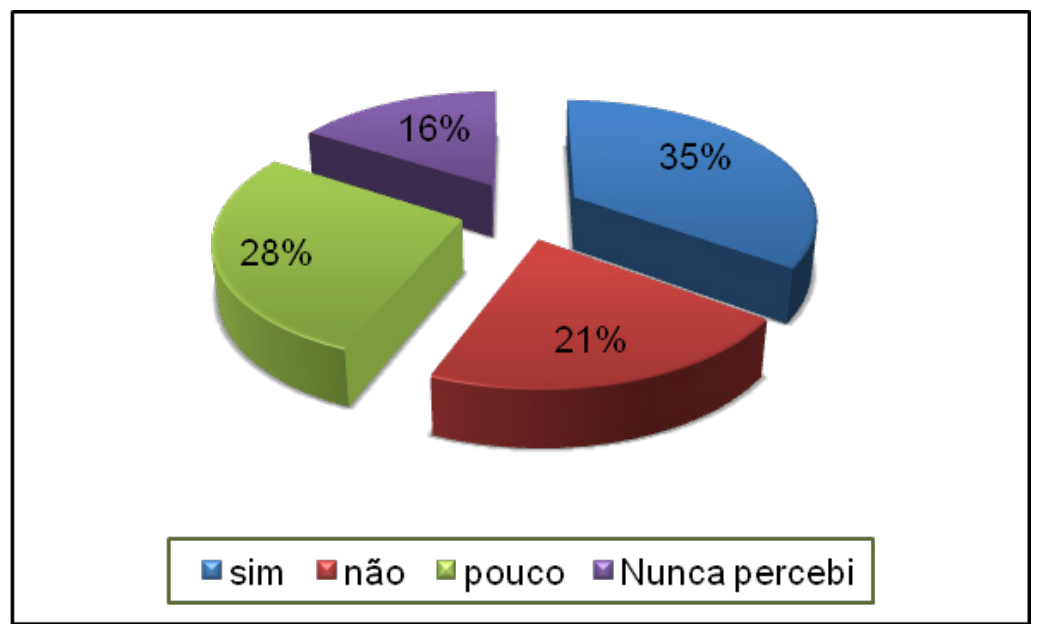

Figura 11 - Reconhecimento nas prateleiras do supermercado de um produto ecologicamente correto.

Em relação ao consumo de arroz com as práticas ambientais (Figura 12), 91\% dos entrevistados acreditam que possa trazer benefícios à saúde, em relação ao produto convencional, $4 \%$ acreditam que traga poucos benefícios; outros $4 \%$ não acreditam que possa trazer algum benefício e $1 \%$ dos entrevistados disseram ser indiferentes.

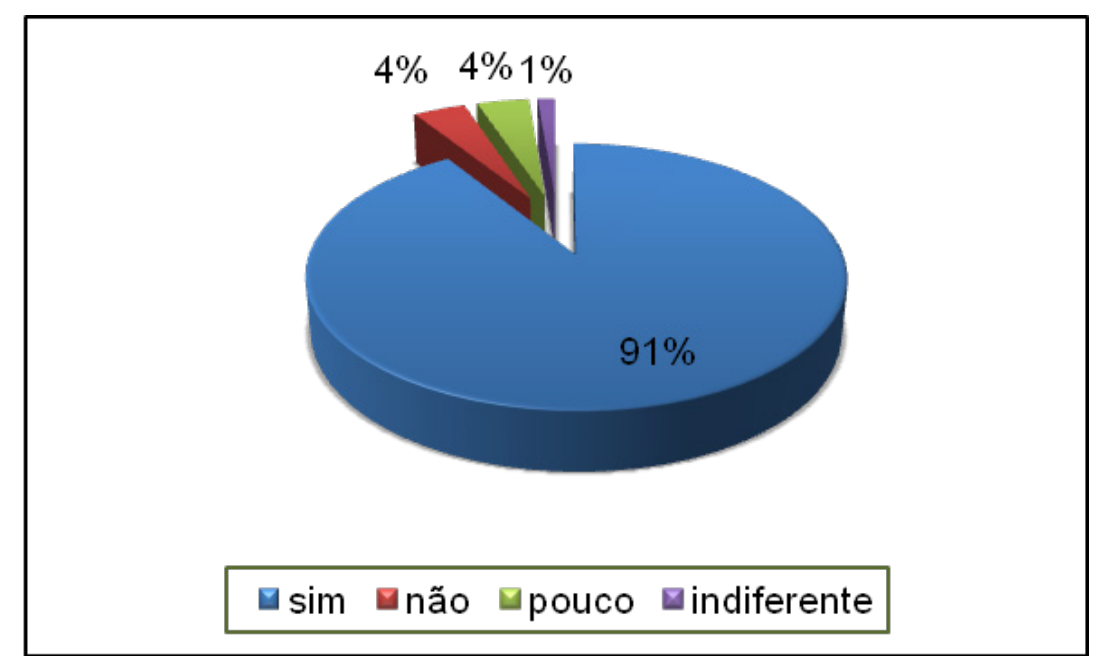

Figura 12 - O Arroz ecologicamente correto pode trazer benefícios à saúde, em relação ao produto convencional. 
Verificou-se, conforme as respostas dos entrevistados na Figura 12, que as práticas ambientais adotadas na lavoura orizícola trazem benefícios à saúde, pois adotam o sistema de racionalização do uso de agrotóxicos, sementes certificadas, uso racional da água entre outras recomendações que contribuem com o bem estar e qualidade do produto arroz.

Quanto à identificação na embalagem, como, por exemplo, o selo ambiental da lavoura de arroz irrigado do rio grande do sul, $85 \%$ dos respondentes disseram atribuir uma maior credibilidade ao produto arroz, $6 \%$ relatou que talvez traga algum crédito ao produto, já $6 \%$ dos entrevistados relataram que não atribui credibilidade, e 3\% são indiferentes à questão (Figura 13).

Alguns entrevistados concordam que a embalagem diferenciada não atribui credibilidade ao produto. Já a maioria respondeu que traz credibilidade, desde que tenha uma identificação diferenciada das demais, como uma embalagem verde, ecologicamente correta.

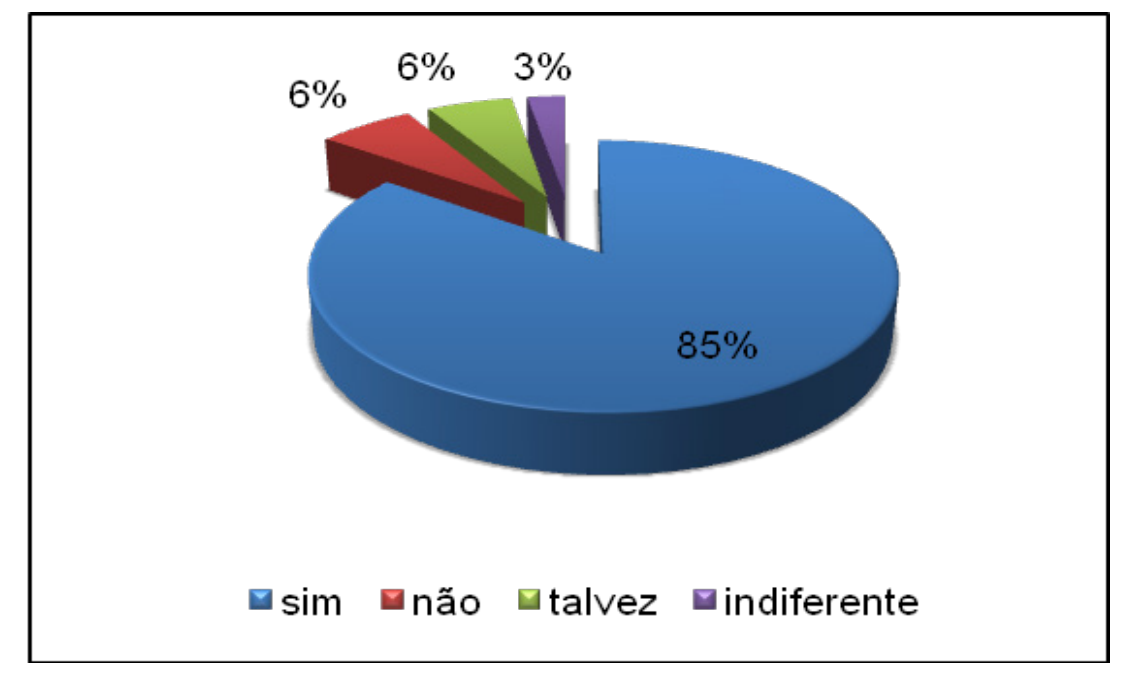

Figura 13 - Identificação na embalagem de arroz com o selo ambiental na lavoura de arroz irrigado do RS atribui credibilidade ao produto.

\subsection{PROMOÇÃo do PRODUTO ECOLOGICAMENTE CORRETO}

$\mathrm{Na}$ Figura 14, referente ao diferencial na embalagem do produto final, cento e quarenta e dois entrevistados responderam ser importante essa identificação para diferenciá-lo do convencional e do concorrente.

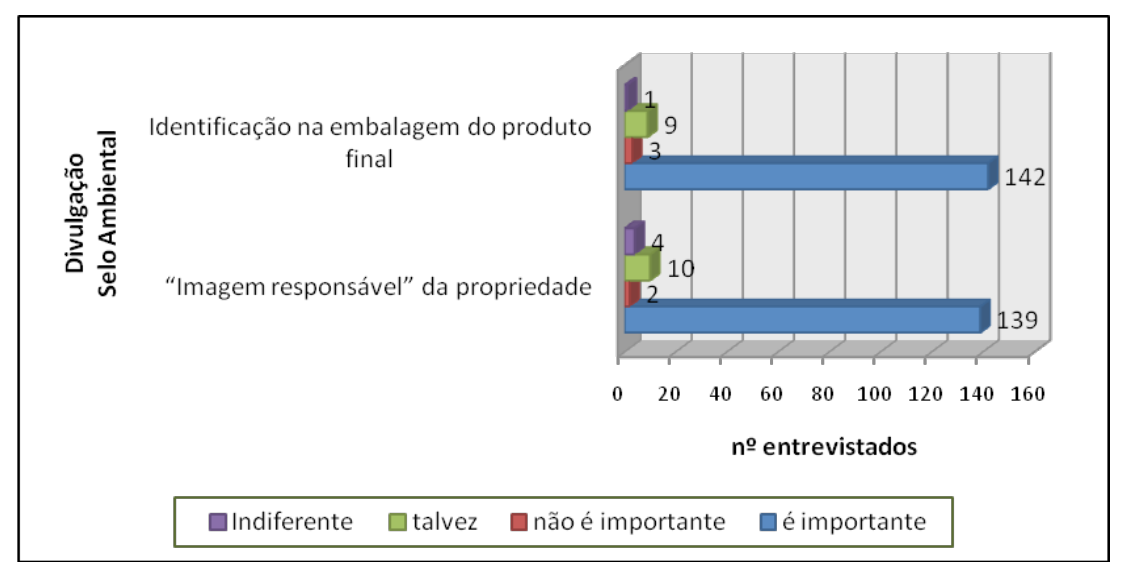

Figura 14 - Divulgação do selo ambiental quanto à "imagem responsável" da propriedade orizícola e identificação na embalagem do produto final que obteve esse prêmio. 
Quanto à divulgação das propriedades que cultivam o arroz certificado, cento e trinta e nove respondentes disseram ser importante a divulgação de "imagem responsável" da propriedade orizícola com selo ambiental da lavoura de arroz irrigado do Rio Grande do Sul perante o mercado, dez respondentes acreditam que talvez seja importante essa divulgação, quatro dos entrevistados disseram ser indiferente a divulgação do selo ambiental e dois afirmaram que para eles não é importante essa divulgação (Figura 14).

Conforme os resultados é importante a identificação das embalagens do produto arroz ecologicamente correto nas prateleiras do supermercado, além da divulgação da propriedade orizícola que adota essas práticas ecologicamente corretas, sendo destacada como uma "lavoura responsável".

No que se refere ao conhecimento do produto arroz com selo ambiental da lavoura de arroz irrigado do RS, $75 \%$ afirmaram desconhecer divulgações referentes ao selo ambiental, $15 \%$ já tiveram conhecimento através da rádio, televisão e jornais, $7 \%$ mediante internet e $3 \%$ por meio de panfletos e outdoor (Figura 15).

Observa-se mais uma vez, que há pouco conhecimento do consumidor sobre a certificação com o selo ambiental na lavoura orizícola.

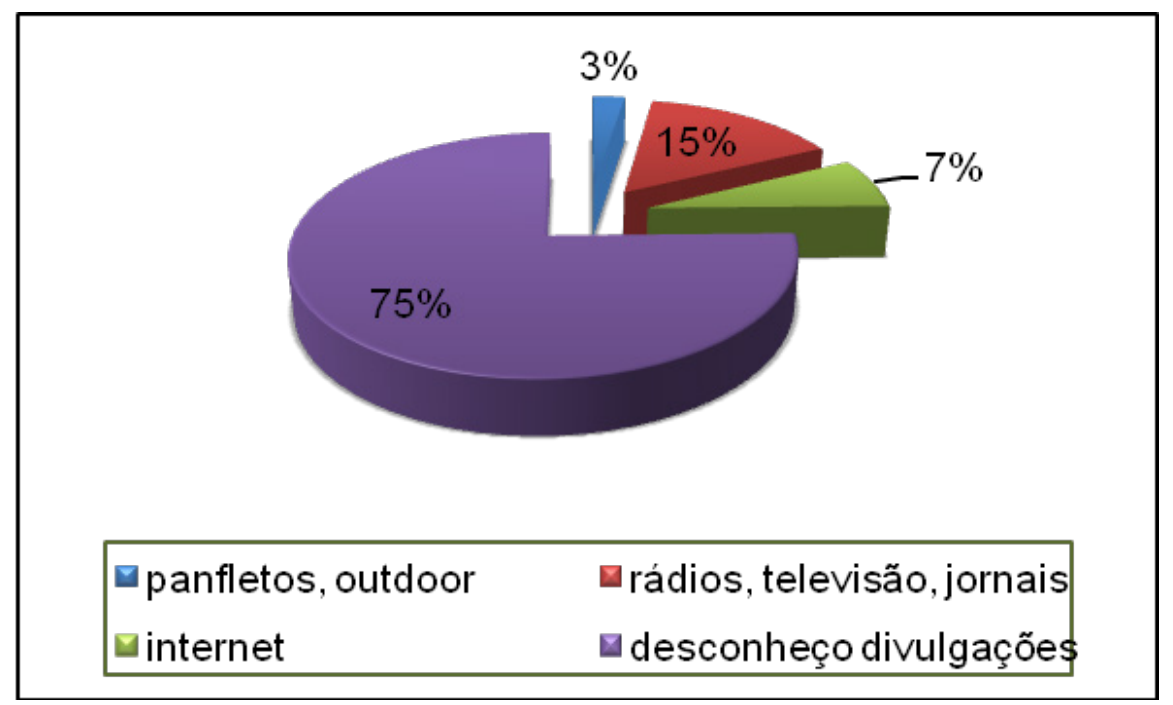

Figura 15 - Divulgações na mídia.

Quanto aos meios de comunicação que poderiam ser utilizados para a divulgação desse produto final (arroz) certificado, 55\% dos respondentes sugeriram a televisão e rádio, $22 \%$ mediante jornais, outros $22 \%$ através da internet e somente $1 \%$ através de outros mecanismos de divulgação como no próprio supermercado (Figura 16).

Reforça-se, portando, que há a necessidade de investir em divulgações, talvez iniciar em emissoras de rádios, por ser menos onerorosa e alcançar um número considerável de ouvintes.

Em relação as informações na embalagem do produto final (arroz) certificado com o selo ambiental da lavoura de arroz irrigado do RS, 39\% relataram ser interessante destacar que é um produto ecologicamente correto, $38 \%$ responderam ser importante destacar na embalagem o logotipo do selo ambiental, $20 \%$ dos entrevistados disseram que seria interessante salientar as regiões que adotam essas práticas ambientalmente corretas e $3 \%$ acreditam que outras informações como os benefícios à saúde e uma cor diferenciada dessa embalagem seriam importante evidenciar (Figura 17).

Nota-se que para os consumidores seria interessante informar na embalagem do arroz a certificação com o selo ambiental do IRGA e, também, adicionar informações de que o produto adota as práticas ecologicamente corretas.

A Figura 18 refere-se ao material para confecção da embalagem. Cerca de 59\% dos entrevistados imaginariam que a embalagem biodegradável se adequaria melhor ao produto do arroz com o selo ambiental da lavoura de arroz irrigado do RS, 20\% informaram que se adequaria melhor uma embalagem a partir da casca de arroz, 12\% declararam ser indiferentes à questão, 5\% optaram pela 


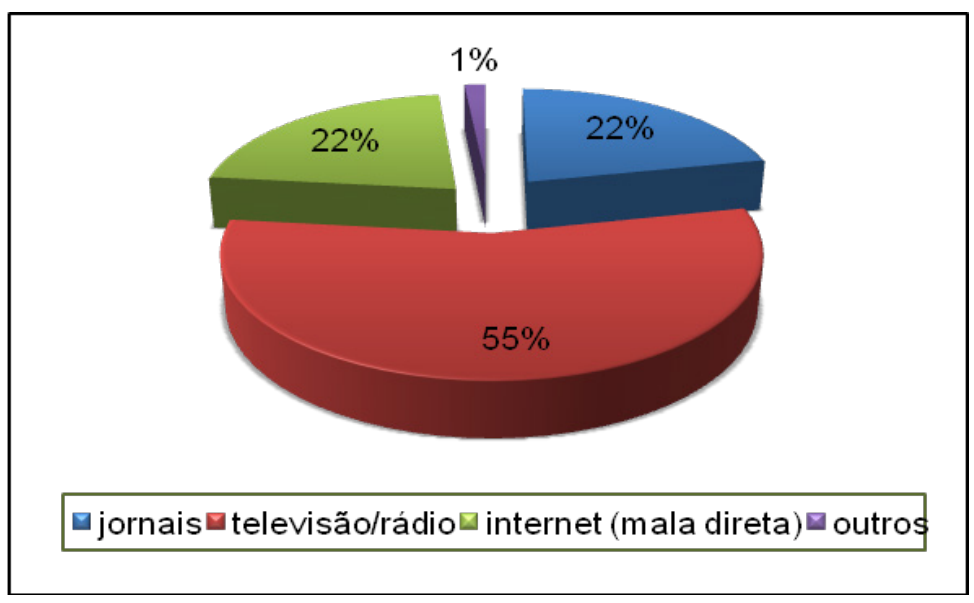

Figura 16 - Meios de comunicação para melhor divulgação do produto final com o selo ambiental do IRGA.

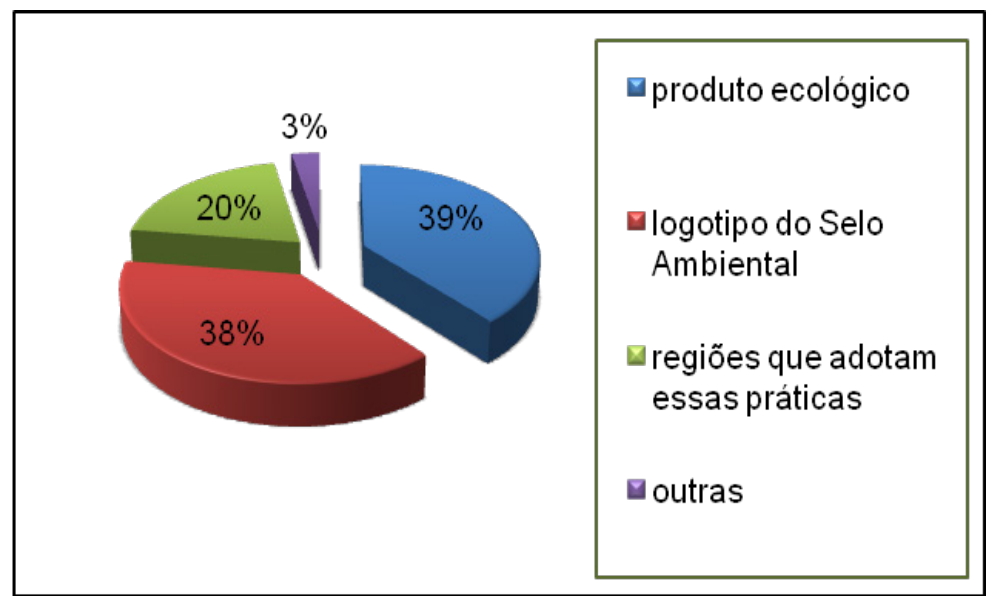

Figura 17 - Informações na embalagem do produto final (Arroz) certificado com o selo ambiental da lavoura de arroz irrigado do RS.

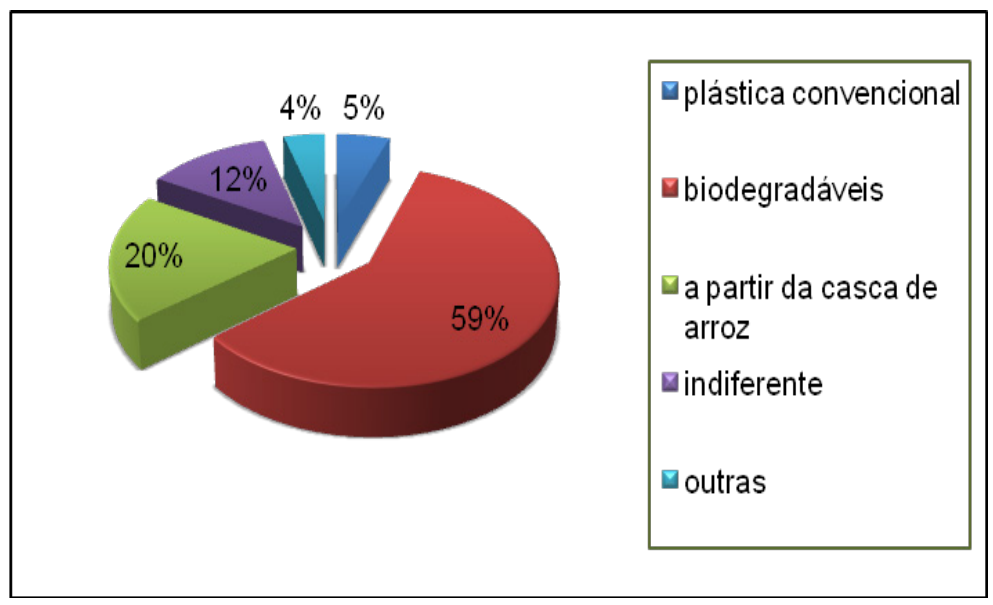

Figura 18 - Material para confecção da embalagem do produto final (arroz) certificado com o selo ambiental da lavoura de arroz irrigado do RS. 
embalagem plástica convencional e somente $4 \%$ informaram outros tipos de embalagens verdes, como a partir da cana-de-açucar ou mesmo da mandioca.

Percebe-se o cuidado do consumidor no que se refere a embalagem, pois a maioria respondeu que a embalagem biodegradável e a partir da casca do arroz, se adequariam melhor a esse produto ecologicamente correto, completando, assim, o ciclo da cadeia produtiva orizícola.

Enfim, pretende-se divulgar essas informações sobre o composto de marketing ambiental para os produtores orizícolas, os técnicos do IRGA e os consumidores finais, a fim de que todos compreendam os benefícios ao meio ambiente. Sem dúvida, é importante informar à sociedade sobre o consumo e práticas ecologicamente corretas, como é o caso das iniciativas adotadas na lavoura orizícola através do P10 e da certificação com o selo ambiental da lavoura de arroz irrigado do Rio Grande do Sul.

\section{CONCLUSÕES}

O Rio Grande do Sul produz 62\% da produção de arroz do Brasil (IRGA, 2010). O Instituto Rio Grandense do Arroz tem grande participação no sistema produtivo orizícola, gerando e disseminando conhecimentos técnicos e científicos, para melhorias de gestão, produtividade e rentabilidade na lavoura orizícola. Alguns dos aspectos que tem sido foco desta instituição de pesquisa atualmente são: Tecnologias mais limpas, Projeto 10 e Selo Ambiental da lavoura de arroz irrigado do Rio Grande do Sul. Estas pesquisas são direcionadas, principalmente, para o manejo das lavouras orizícolas.

O comportamento do consumidor dos produtos orizícolas ecologicamente corretos tem sido pouco investigado. Este trabalho foi elaborado para subsidiar o setor orizícola com informações que direcionem as decisões ambientalmente estratégicas, como a definição da embalagem do arroz certificado com o selo ambiental do IRGA, que até o momento não foi definida.

Quanto ao preço ecologicamente correto os consumidores assumiram que podem pagar um adicional por este produto ecologicamente correto, porém, esse preço não poderá ser muito maior que o produto convencional.

Já na promoção do produto ecologicamente correto, verificou-se que há a necessidade de se identificar a certificação com o selo ambiental da lavoura de arroz no produto final, arroz beneficiado. Observou-se na pesquisa a importância de informar toda a cadeia produtiva orizícola, principalmente o consumidor final, sobre as características diferenciadas desse produto.

Para os consumidores, é importante a divulgação da propriedade rural que produz esse arroz certificado e a identificação de seus benefícios na embalagem do produto final, para que possam distinguir esse produto do convencional. A televisão, rádio e jornais são os meios de comunicação recomendados por esse público para a divulgação de informações referentes a esses produtos.

Em relação ao ponto de venda do produto ecologicamente correto, a principal constatação, nas entrevistas com os consumidores, foi de que não há o reconhecimento dos clientes no momento da compra dos produtos ecologicamente corretos (como embalagens e conteúdos biodegradáveis e recicláveis), dispostos nas gôndolas, uma vez que não há diferenciação de produtos.

O baixo poder aquisitivo da maioria da população entrevistada e a pouca compreensão dos problemas ambientais, representam fortes obstáculos à adesão aos apelos ecologicamente corretos e, consequentemente, a aquisição dos produtos produzidos em sistemas orizícolas ecologicamente corretos.

Por isso, os consumidores salientaram a necessidade de divulgação, nos rótulos e na mídia, de informações sobre os benefícios do consumo desses produtos em relação aos produtos convencionais.

Sugere-se para outras pesquisas, a realização de um estudo detalhado da melhor embalagem para o produto certificado com o selo ambiental do IRGA. Indica-se a utilização de materiais e processos industriais de baixo impacto ou a reutilização do produto após o descarte (que seria uma embalagem ambientalmente correta e que estaria em conformidade com a imagem do produto), levando em conta os impactos ambientais ao longo de todo o ciclo de vida - para o produto final do arroz certificado com o selo ambiental - destacando a identificação do produto que é produzido com práticas ambientais de menor impacto nas lavouras. 


\section{REFERÊNCIAS}

ALIGLERI, L.; ALIGLERI, L. A.; KRUGLIANSKAS, I. Gestão socioambiental: responsabilidade e sustentabilidade do negócio. São Paulo: Atlas, 2009.

BECHERT, M. Lavoura Arrozeira. IRGA 70 anos a serviço da lavoura arrozeira: Abertura da Colheita. Porto Alegre: Instituto Rio Grandense do Arroz. Volume 58, número 453, Maio 2010.

BERKOWITZ, E. N.; KERIN, R. A.; HARTLEY, S. W.; RUDELIUS, W. Marketing. $6^{a}$ Edição, Rio de Janeiro: LTC Editora, 2003.

BERTÉ, R. Gestão socioambiental no Brasil. Edição Especial. Curitiba: Ibpex, 2009.

DEON, L. B. Lavoura Arrozeira. IRGA 70 anos a serviço da lavoura arrozeira: Constituintes do arroz. Porto Alegre: Instituto Rio Grandense do arroz. Volume 58, número 453, Maio 2010.

DIAS, R. Marketing Ambiental: Ética, responsabilidade social e competitividade nos negócios. 1. Ed. 2007 3. reimpr. - São Paulo: Atlas, 2009.

EMBRAPA. Arroz e feijão: História do arroz. Disponível em: <http://www.cnpaf.embrapa.br/arroz/historia. htm> Acesso em: 07 set. 2010.

FAO. Rice is life: International Year of Rice, 2004. Disponível em: <http://www.fao.org/rice2004/es/aboutrice.htm>. Acesso em: 07 set 2010.

GLIESSMAN, S. R. Agroecologia: Processos Ecologicamente corretos em Agricultura Sustentável. 4. Ed. Porto Alegre: Ed. Universidade/UFRGS, 2009.

IBGE. Dados da Lavoura Temporária 2009 do Município de São Gabriel. Disponível em: http://www.ibge. gov.br/cidadesat/topwindow.htm?1 Acesso em 02/05/2011.

IRGA. Instituto. Disponível em:<http://www.irga.rs.gov.br> Acesso em 14 ago. 2010.

KOTLER, P.; ARMSTRONG, G. Princípios de marketing. 7ª Edição, Rio de Janeiro: LTC Editora, 1999.

KOTLER, P. Administração de Marketing: a Edição do Milênio. 10ª . ed. Prentice-Hall: São Paulo, 2000.

MEDEIROS, J. F. de; CRUZ, C. M. L. Comportamento do consumidor: fatores que influenciam no processo de decisão de compra dos consumidores. Teor. e Evid. Econ. Passo Fundo v. 14 Ed. Especial p. 167-190 2006.

MILARÉ, É. Direito do Ambiente: A Gestão do ambiente em foco: doutrina, jurisprudência, glossário. Prefácio à 5. Ed. Ada Pellegrini Grinover. 5. Ed. ref., atual. e ampl. - São Paulo: Editora Revista dos Tribunais, 2007.

PHILIPPI Jr., A; ROMÉRO, M de A; BRUNA, G. C.; editores. Curso de Gestão Ambiental. Coleção Ambiental; 1. Barueri, SP. Ed. Manole/USP, 2004.

ROSA, G. R. da. Revista Planeta ARROZ. Planta Arroz. Tá Limpo: Tecnologias mais limpas mostram que o impacto ambiental da lavoura de arroz é menor do que se pensava. Ano 10. Edição 37. Dezembro, 2009. Casa Brasil Editores Ltda. Disponível em: <http://www.planetaarroz.com.br/flip/ed32/> Acesso em: $1^{\circ}$ set. 2010.

TULESKI, Y. M. Mix de Marketing: 4 P's (Produto, Preço, Promoção e Praça) CEDET - Centro de Desenvolvimento Profissional e Tecnológico. Atualizado em 11 maio 2009. Disponível em: <http://www.cedet. 
com.br/index.php?/Tutoriais/Marketing/mix-de-marketing-4-pas-produto-preco-promocao-e-praca. html> Acesso em 12 ago. 2010.

VIEIRA, V. A. Fazendo uma revisão nas áreas de influência no comportamento do consumidor. REAd - Edição 29 Vol. 8 No. 5, set-out 2002.

VINÍCIUS, M. Ecologia: Questões ambientais. Disponível em: <http://www.universitario.com.br/celo/topicos/subtopicos/ecologia/questoes_ambientais/questoes_ambientais.html> Acesso em: 05 ago. 2010.

\section{APENDICE A - QUESTIONÁRIO PARA OS CONSUMIDORES DE PRODUTOS ECOLOGICAMENTE CORRETOS}

Consumidor:

Profissão:

Data Entrevista:

Local Entrevista:

\section{GRUPO 1 - CARACTERIZAÇÃO DOS CONSUMIDORES}

1. Com que frenquência o $\mathrm{Sr} / \mathrm{Sr}^{\mathrm{a}}$ vai ao supermercado:

a. ( ) diáriamente

b. ( ) 2 vezes por semana

c. ( ) 3 a 4 vezes por semana

d. ( ) semanalmente

e. ( ) quinzenalmente

f. ( ) mensalmente

2. Qual sua formação escolar:

a. ( ) fundamental incompleto

b. ( ) fundamental completo

c. ( ) ensino médio incompleto

d. ( ) ensino médio completo

e. ( ) ensino superior incompleto

f. ( ) ensino superior completo

3. Sua renda mensal:

a. ( ) até 510,00

b. ( ) de $\mathrm{R} \$ 511,00$ a $\mathrm{R} \$ 1.530,00$

c. ( ) de $\mathrm{R} \$ 1.531,00$ a $\mathrm{R} \$ 3.060,00$

d. ( ) de $\mathrm{R} \$ 3.061,00$ a $\mathrm{R} \$ 4.590,00$

e. ( ) acima de $\mathrm{R} \$ 4.591,00$

\section{GRUPO 2 - PRODUTO ECOLOGICAMENTE CORRETO}

4. Quanto a postura de um consumo consciente, das opções abaixo quais o $\mathrm{Sr} / \mathrm{Sr}^{\mathrm{a}}$ tem o cuidado de adotar em sua casa ou local de trabalho:

a. ( ) reciclagem (separação de resíduos - lixo), como: não misturar os papéis limpos, vidros, plásticos, metais com o lixo comum (orgânicos). 
b. ( ) reutilização de materiais, como por exemplo, usando os dois lados do papel, esse ato aumenta a vida útil dos produtos e materiais e evita o desperdício de recursos.

c. ( ) redução, consumir apenas o necessário e evitar a geração de lixo, como recusar sacolas e sacos plásticos, evitar embalagens desnecessárias e uso de produtos descartáveis.

d. ( ) Nenhuma das práticas acima.

e. ( ) Outra prática que não foi mencionada. Qual?

5. Quanto a compra de produtos no supermercado, o $\mathrm{Sr} / \mathrm{Sr}^{\mathrm{a}}$ se preocupa em escolher produtos ecológicamente corretos:
a. ( ) frequentemente
b. ( ) raramente
c. ( ) nunca

6. Para o $\mathrm{Sr} / \mathrm{Sr}^{\mathrm{a}}$ há diferença na qualidade do produto ecologicamente correto do produto convencional?
a. ( ) $\operatorname{sim}$
b. ( ) não
c. ( ) nunca comparei

7. $\mathrm{O} \mathrm{Sr} / \mathrm{Sr}^{\mathrm{a}}$ conhece as práticas ecológicas adotadas na lavoura de arroz no Estado do RS?
a. ( ) muito
b. ( ) pouco
c. ( ) não tenho conhecimento

8. As propriedades orizícolas que adotam as práticas ambientalmente corretas se increvem para concorrerem ao Selo Ambiental na lavoura de arroz. O Sr/Sra conhece o Selo Ambiental:
a. ( ) muito
b. ( ) pouco
c. ( ) não tenho conhecimento

\section{GRUPO 3 - PREÇO ECOLOGICAMENTE CORRETO}

9. O Sr/Sra pensa que o produto ecológico poderá despertar uma consciência eco-social, educando, por exemplo, o Sr/Sra e a indústria:
a. $\quad(\quad) \operatorname{sim}$
b. ( ) não

10. $\mathrm{O} \mathrm{Sr} / \mathrm{Sr}^{\mathrm{a}}$ acha que estas práticas ecológicas contribuem para o aumento da demanda por esses produtos:
a. ( ) contribui
b. ( ) não contribui
c. ( ) talvez

11. O aumento da produção de produtos ecológicos no Brasil tem levado os agricultores a buscarem pontos mais diversificados para a comercialização. $\mathrm{O} \mathrm{Sr} / \mathrm{Sr}^{\mathrm{a}}$ pagaria "mais" por um produto ecológico e com certificação:
a. ( ) sim
b. ( ) não

GRUPO 4 - DISTRIBUIÇÃO DO PRODUTO ECOLOGICAMENTE CORRETO 
12. $\mathrm{O} \mathrm{Sr} / \mathrm{Sr}^{\mathrm{a}}$ tem preferência por produtos:

a. ( ) produto de base ecológica local

b. ( ) produto de base convencional local

c. ( ) Indiferente

13. $\mathrm{O} \mathrm{Sr} / \mathrm{Sr}^{\mathrm{a}}$ reconhece um produto ecológico nas prateleiras do supermercado:

a. ( ) $\operatorname{sim}$

b. ( ) não

c. ( ) Nunca percebi.

14. $\mathrm{O} \mathrm{Sr} / \mathrm{Sr}^{\mathrm{a}}$ acredita que o consumo de arroz com as práticas ambientais possa trazer benefícios à saúde, em relação ao produto convencional:
a. ( ) muito
b. ( ) pouco
c. ( ) indiferente

15. $\mathrm{O} \mathrm{Sr} / \mathrm{Sr}^{\mathrm{a}}$ acredita que a identificação na embalagem como o Selo Ambiental possa atribuir maior credibilidade ao produto "arroz":
a. ( ) é importante
b. ( ) não é importante
c. ( ) talvez
d. ( ) Indiferente

\section{GRUPO 5 - PROMOÇÃO DO PRODUTO ECOLÓGICO}

16. Quanto à divulgação das propriedades que cultivam o arroz ecológico (Selo Ambiental) entre a população, o $\mathrm{Sr} / \mathrm{Sr}^{\mathrm{a}}$ acha importante a divulgação de "imagem responsável" da propriedade orizícola com Selo Ambiental perante o mercado:
a. ( ) é importante
b. ( ) não é importante
c. ( ) talvez
d. ( ) Indiferente

17. Na sua opinião é importante obter um diferencial (identificação) na embalagem do produto final que obteve o Selo Ambiental para diferenciá-lo do convencional e de seu concorrente:
a. ( ) interessante
b. ( ) muito interessante
c. ( ) pouco interessante
d. ( ) Indiferente

18. Que divulgação na mídia, o $\mathrm{Sr} / \mathrm{Sr}^{\mathrm{a}}$ conhece focando o arroz com Selo Ambiental?
a. ( ) panfletos, out-door
b. ( ) rádios, televisão, jornais
c. ( ) desconheço divulgações
d. ( ) outros:

19. Que meios de comunicação poderiam ser utilizados para a divulgação desse produto final (arroz) certificado:
a. ( ) jornais
b. ( ) televisão/rádio
c. ( ) internet (mala direta)
d. ( ) outros: 
20. Quais as informações que o $\mathrm{Sr} / \mathrm{Sr}^{\mathrm{a}}$ acharia interessante destacar na embalagem do produto final (arroz) certificado com o Selo Ambiental:
a. ( ) produto ecológico
b. ( ) logotipo do Selo Ambiental
c. ( ) regiões que adotam tal práticas
d. ( ) outras:

21. Que tipo de embalagem o $\mathrm{Sr} / \mathrm{Sr}^{\mathrm{a}}$ imaginaria que se adequaria ao produto do arroz com o Selo Ambiental:
a. ( ) embalagens biodegradáveis
b. ( ) embalagens a partir da casca de arroz
c. ( ) embalagens a partir da cana-de-acúcar
d. ( ) emblagem a partir da mandioca 